\title{
P02.81. Symptom management with massage in postoperative colorectal patients: a randomized controlled trial
}

\author{
N Delzer, B Bauer \\ From International Research Congress on Integrative Medicine and Health 2012 \\ Portland, Oregon, USA. 15-18 May 2012
}

\section{Purpose}

We analyzed the impact of post-operative massage in patients who had undergone abdominal colorectal surgery.

\section{Methods}

A randomized-controlled trial was designed for colorectal abdominal surgery patients. Patients were randomized to either receive a 20 minute massage on POD 1 and 2, 20 minutes of ambulation, or a visit by the massage therapist (no massage). Baseline physiologic data (HR, SBP/DBP, $\mathrm{RR})$ were collected 30 minutes prior to and after either intervention. A standardized assessment of patient perception of pain, tension, anxiety, satisfaction with overall care, and relaxation level utilizing a visual analog scale (10 point Likert scale) was obtained before and after the intervention. The IRB approved study was powered to detect a difference at the $80 \%$ level. Repeated measures models were used to compare the symptom scores at different time points. T-tests were used to compare same day pre-post intervention changes.

\section{Results}

128 patients (62 massage [M], 66 control [C]) were randomized. There was no statistical difference between the groups in regards to age, gender, diagnosis, history of prior abdominal surgery, or mode of surgery (open vs. laparoscopic). Over the first two post-operative days, $M$ patients experienced a significant reduction in anxiety $(\mathrm{p}=0.01)$ and improvement in relaxation $(\mathrm{p}=0.003)$ but not in pain $(p=0.15)$, tension $(p=0.11)$, or satisfaction $(p=0.21)$ as compared to $C$ patients. The only physiologic variable altered was a reduction in diastolic BP $(p=0.04)$ in the $M$

Mayo Clinic, Rochester, USA group. A comparison between baseline, prior to any intervention, and after intervention on POD1 demonstrated the $M$ patients experienced a reduction in pain, tension, anxiety, and an improvement in relaxation relative to $C$ patients. The same holds on POD2 pre-post intervention.

\section{Conclusion}

In a randomized controlled trial of patients undergoing abdominal colorectal surgery, we demonstrated that postoperative massage resulted in a significant improvement of patient's perception of post-operative pain, tension, and anxiety.

Published: 12 June 2012

doi:10.1186/1472-6882-12-S1-P137

Cite this article as: Delzer and Bauer: P02.81. Symptom management with massage in postoperative colorectal patients: a randomized controlled trial. BMC Complementary and Alternative Medicine 201212 (Suppl 1):P137.

Submit your next manuscript to BioMed Central and take full advantage of:

- Convenient online submission

- Thorough peer review

- No space constraints or color figure charges

- Immediate publication on acceptance

- Inclusion in PubMed, CAS, Scopus and Google Scholar

- Research which is freely available for redistribution 